\title{
Una apuesta por el futuro
}

Revista de Oncología ha cumplido 2 años, período insuficiente para valorar la trascendencia e impacto de una publicación científica, pero suficiente para llegar a valorar sus posibilidades para afrontar el futuro en un ambiente de alta competencia como es el mundo editorial especializado. En esta exposición queremos dejar constancia de la importancia de que una publicación de habla no inglesa alcance un prestigio y una difusión global, así como de nuestro compromiso con una metodología homologada a nivel internacional. Este esfuerzo sería baldío sin una metódica rigurosa y ambiciosa que despeje con rapidez las dudas sobre la viabilidad de la revista y la capacidad de alcanzar las metas propuestas. Un esfuerzo que requerirá además el contraste frente a una audiencia internacional para conseguir su validación.

Una revista científica de ámbito internacional debe poder afrontar con éxito el envite del tiempo y asentarse entre los lectores como un hábito necesario para el buen desarrollo de su profesión. Ésta es una meta incuestionable para Revista de Oncología. La calidad debe ser la premisa sobre la que asentar cualquier posibilidad de consolidación y desarrollo, y sólo un reconocido grupo de expertos puede ejecutar esta labor con garantías. Por ello, Revista de Oncología basa en el sistema de evaluación por pares la consideración de aceptar o rechazar un trabajo original, editorial, nota clínica, etc., que se nos confíe.

El amplio espectro de los trabajos que se publicarán en Revista de Oncología nos obliga a disponer de un amplio número de expertos agrupados en el Comité Editorial. Este cuerpo de apoyo a la labor editorial será moldeado para cubrir las necesidades según transcurra el tiempo y el grado de profesionalidad en las respuestas de cada experto. La intervención del equipo editorial será una obligación para velar por la transparencia y equidad del sistema. También será necesario ejecutar una política editorial y una toma de decisiones mismo trabajo o al recibir evaluaciones de insuficiente calidad. En todas las ocasiones se aplicará un criterio uniforme y riguroso para velar por la calidad y homogeneidad de lo publicado. Por último, se prestará una atención especial a cumplir plazos razonables en completar el proceso de evaluación. de llegar a todos los profesionales de la Oncología, aunque tenga un marcado acento en el mundo iberoamericano. Como órgano oficial de expresión de la FESEO, Revista de Oncología es, sin duda, la más codirectas al recibir opiniones contradictorias sobre un

Revista de Oncología nace con una vocación universal

nocida y divulgada de las revistas españolas especializadas en el ámbito de la oncología. Se ha renovado recientemente con la ambición de colocarse en breve tiempo entre las revistas más leídas en oncología a nivel mundial, y ciertamente entre los oncólogos iberoamericanos. Como primer medida hacia la internacionalización se ha hermanado con otra revista del ámbito oncológico con un reconocido prestigio y una importante divulgación en América, la revista del Instituto Nacional de Cancerología de México. La fuerza de ambas revistas unidas supone ampliar el ámbito de influencia de forma espectacular, facilitando su penetración internacional y la captación de artículos de calidad que redunde en su mayor difusión.

La internacionalización de Revista de Oncología se logra sin ambigüedades ya desde este primer número tras la fusión, con la incorporación de un panel de prestigiosos editores asociados de varios países de Europa, América y Asia. Su colaboración será un garante de control de la calidad en los contenidos de la revista y un acicate para la captación de artículos de todos los continentes. Nuestro compromiso alcanza, por tanto, también la faceta de buscar la confianza de nuestros colegas a nivel internacional y hacer de Revista de Oncología una publicación útil. Por ello se trabajará con tenacidad e ilusión para conseguir la inclusión de $R e$ vista de Oncología en los referentes internacionalmente aceptados actualmente como estándar, tales como Medline y Current Contents, entre otros. Este proceso debe culminarse en un período de pocos años y cerrar así un primer ciclo de consolidación. Por último, el acceso electrónico a los resúmenes de los artículos publicados es ya una realidad que se puede constatar en la dirección (http: //www.doyma.es). En un futuro muy próximo el acceso a través de una página web especializada facilitará la consulta y expansión de la Revista.

Si bien la apuesta por la calidad y el rigor metodológico está hecha, todo ello será un esfuerzo fútil y fugaz si no contamos con el apoyo más importante, el de los propios autores, que nos confíen para su publicación en Revista de Oncología los frutos de su labor profesional. Es una inversión en el futuro sin la cual será imposible progresar.

Nuestro agradecimiento a todos los que habéis contribuido ya con vuestros artículos y a los que nos habéis ayudado en la ingrata y anónima labor de evaluar los trabajos recibidos. Confiamos en que este esfuerzo común sirva para alcanzar las metas trazadas en la presentación de esta nueva etapa.

\section{Rafael Rosell ${ }^{\mathrm{a}}$, Alejandro Mohar ${ }^{\mathrm{b}}$} y Juan Carlos Lacal ${ }^{\text {b }}$

Rev Oncología 2001; 3: 4 